\title{
THE EFFECT OF DIETARY LACTOBACILLI ON IN-VITRO CATABOLIC ACTIVITIES OF THE SMALL-INTESTINAL MICROFLORA OF NEWLY WEANED PIGS
}

\author{
I. R. Hill, R. Kenworthy AND P. Porter \\ Unilever Research Laboratory Colworth/Welwyn, Colworth House, \\ Sharnbrook, Bedford
}

FOR many years the true value of dietary lactobacilli in the treatment of certain gastro-intestinaldisorders has remained uncertain. It has generally been believed that any curative action would involve the production and maintenance of acidic conditions in the intestinal tract, thereby creating a habitat unsuitable for growth of enteropathogens. Chemical rather than microbiological control of intestinal $p \mathrm{H}$ has been examined for the same reason (Burnett and Hanna, 1963; Kershaw, Luscombe and Cole, 1966; Cole, Beal and Luscombe, 1968). However, the conflicting reports in the literature suggest that mechanisms other than acidity (e.g., metabolic activity) may be involved.

It is well known that Escherichia coli and strains of some other intestinal micro-organisms can produce amines in culture media containing amino acids (Berthelot and Bertrand, 1912; Eggerth, Littwin and Deutsch, 1939; Gale, 1946). Furthermore, amines and phenols have been identified in the digestive tract of animals (Hanke and Koessler, 1924; Melnykowycz and Johannson, 1955; Perry et al., 1966). The microflora of the pig is known to be active in decarboxylating amino acids (Michel, 1961, 1966, 1968) but in-vivo toxicity of metabolic products absorbed from the gut has not yet been directly demonstrated, although indirect evidence has been accumulated (Anderson et al., 1956; György, 1957; Larson and Hill, 1960; François, 1961 ; Eyssen and de Somer, 1965; Huhtanen and Pensack, 1965).

Previous publications (Porter and Kenworthy, 1969; Hill, Kenworthy and Porter, 1970) have reported increased production of amines in the intestinal tract of young pigs soon after weaning, and described a measure of control over this phenomenon promoted by preincubation of liquid diets with lactobacilli.

The present study compares the in-vitro catabolic activities (decarboxylative and deaminative) in digesta from the small intestines of pigs used in the experiments described by Hill et al. It also attempts to discover a correlation between certain physical characteristics $(p \mathrm{H}$, dry weight and microbial population of digesta, and live weight of pigs) and any changes that may be observed in the clinical criteria under study.

\section{MATERIALS AND METHODS}

Animals

Management systems, numbers of animals, diets, animal liveweights, times of necropsy and sampling of digesta have been previously described (Hill et al.). Two trials were carried out, involving litters of 14 and 10 pigs respectively. Two pigs in each trial were examined

Received 13 Nov. 1969; accepted 13 Apr. 1970.

J. MED. MICROBIOL.-VOL. 3 (1970) 
at necropsy before weaning (day 21), and the remainder were weaned at 21 days on to a diet of reconstituted sterilised spray-dried bovine milk (diet 1) or the same milk incubated with Lactobacillus acidophilus (diet 2), and examined at necropsy at intervals after weaning. Intestinal contents removed immediately after death were examined for their microbial flora and their decarboxylative and deaminative capacity.

\section{Microflora of intestinal digesta}

Micro-organisms were isolated by the use of the following media and incubation conditions.

(a) Nutrient agar (Oxoid CM3) plates were incubated aerobically at $37^{\circ} \mathrm{C}$ for up to 5 days; (b) washed blood agar; Nutrient Agar (Oxoid (CM55) was supplemented with 5 per cent. washed sheep red cells and plates were incubated aerobically at $37^{\circ} \mathrm{C}$ for up to 5 days; (c) Reinforced Clostridial Medium Agar (Oxoid CM151) was supplemented with (i) 5 per cent. citrated sheep blood, (ii) $75 \mu \mathrm{g}$ neomycin per $\mathrm{ml}$, and (iii) 5 per cent. citrated sheep blood and $75 \mu \mathrm{g}$ neomycin per ml. Plates were incubated anaerobically at $37^{\circ} \mathrm{C}$ for up to 5 days; (d) Rogosa agar (Rogosa, Mitchell and Wiseman, 1951) plates were incubated anaerobically at $37^{\circ} \mathrm{C}$ for up to 5 days; (e) Sabouraud Dextrose Agar (Oxoid CM41) plates were incubated aerobically at $25^{\circ} \mathrm{C}$ for up to 5 days; $(f)$ the PPLO agar of Ross and Switzer (1963) was modified by incorporating 0.0125 per cent. thallium acetate instead of methylene blue. Plates were incubated aerobically in a moist atmosphere at $37^{\circ} \mathrm{C}$.

Generally only organisms growing on plates with 60 or fewer colonies were subcultured into tubes of appropriate broth media. Where several distinctive colonies on any one plate appeared identical macroscopically and microscopically, four randomly chosen colonies were taken for purification. On plates from more concentrated inocula than those used for isolation, colonies were observed and stained to determine whether they were of types not found on the plate from less concentrated inocula. If this was so, they were also isolated and purified.

The isolates were purified by the pour-plate method. Discrete colonies were removed from pour plates and purified further if necessary by the same procedure, or, if apparently pure they were checked by Gram staining. A single colony was subcultured on agar, or into broth, for temporary storage.

Bacteria were characterised to the generic level by the tests of Cowan and Steel (1965). Yeasts were identified but not classified.

\section{Decarboxylation and deamination determinations}

$\mathrm{Q}_{\mathrm{CO}_{2}}$ values ( $\mu \mathrm{l}$ of $\mathrm{CO}_{2}$ evolved per hr per mg dry wt of intestinal digesta) were manometrically determined with a Warburg constant-volume respirometer (Umbreit, Burris and Stauffer, 1957). $\mathrm{Q}_{\mathrm{NH}_{3}}$ values were obtained from ammonia analyses (Koch and Hanke, 1953) of the Warburg flask liquor at the termination of the experimental period.

Samples of the whole intestinal digesta were taken and immediately incubated, either as unamended non-buffered suspensions or supplemented with the amino acids $l$-arginine, $l$-histidine, $l$-lysine and $l$-ornithine (or an equivalent volume of 0.85 per cent. saline) to a final concentration of $0.02 \mathrm{M}$. Control flasks for carbon dioxide absorption were included. Flasks were incubated anaerobically (in an atmosphere of nitrogen) at $37^{\circ} \mathrm{C}$. As incubation periods of greater than $10 \mathrm{hr}$ frequently led to inconsistent fluctuations in carbon dioxide evolution, the $\mathrm{Q}_{\mathrm{CO}_{2}}$ and $\mathrm{Q}_{\mathrm{NH}_{3}}$ values were determined per $\mathrm{hr}$ over a period of $8 \mathrm{hr}$.

\section{Amino acid analyses}

Amino acids were analysed with a Technicon Autoanalyser (Technicon Instrument Co. Ltd, Chertsey, Surrey). The method of Thomas (1966) was followed, modified by the use of 5.5 per cent. methanol in chamber 1 and of a flow rate of $60 \mathrm{ml}$ per $\mathrm{hr}$. 


\section{RESULTS}

\section{Microbial populations of digesta}

In trials 1 and 2 the small-intestinal digesta supported populations of streptococci, lactobacilli, clostridia, Escherichia coli and yeasts (fig. 1). In trial 1 Bacteroides and Proteus were also isolated from digesta.

Trial 1
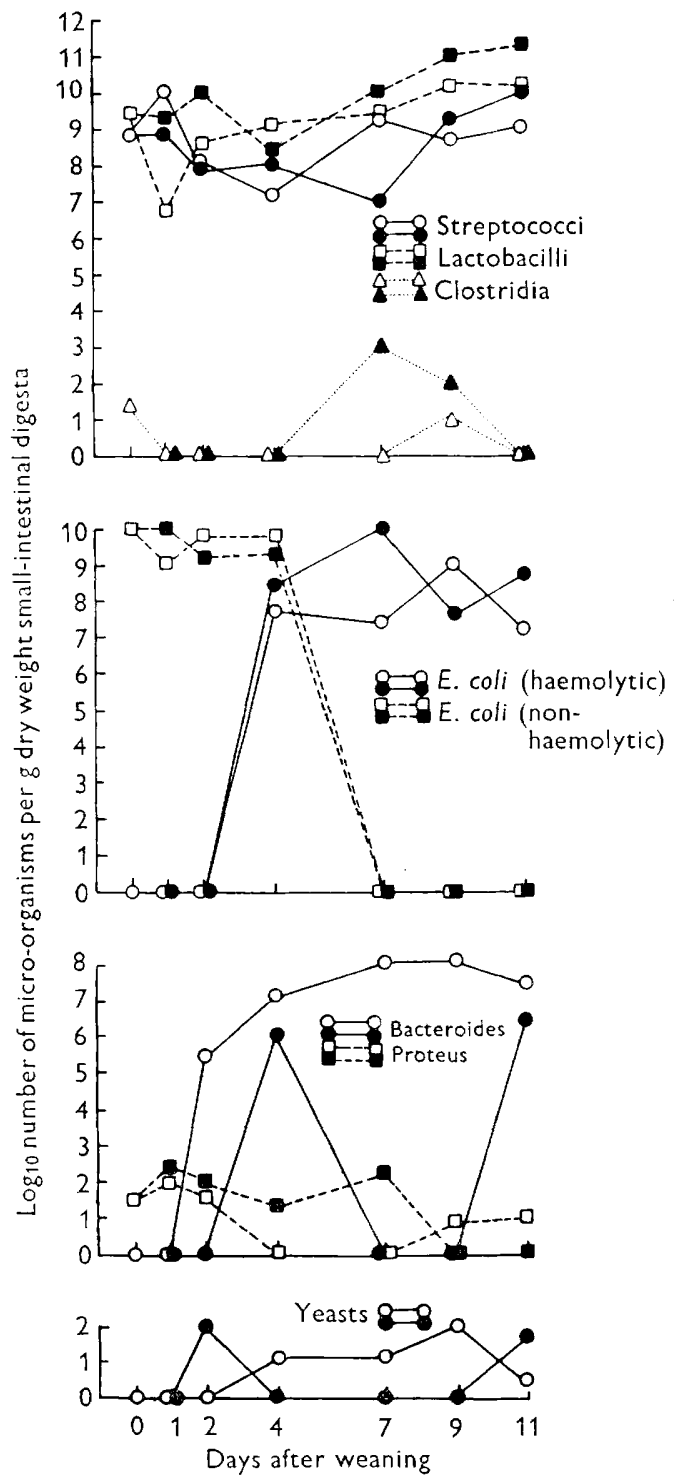

Trial 2
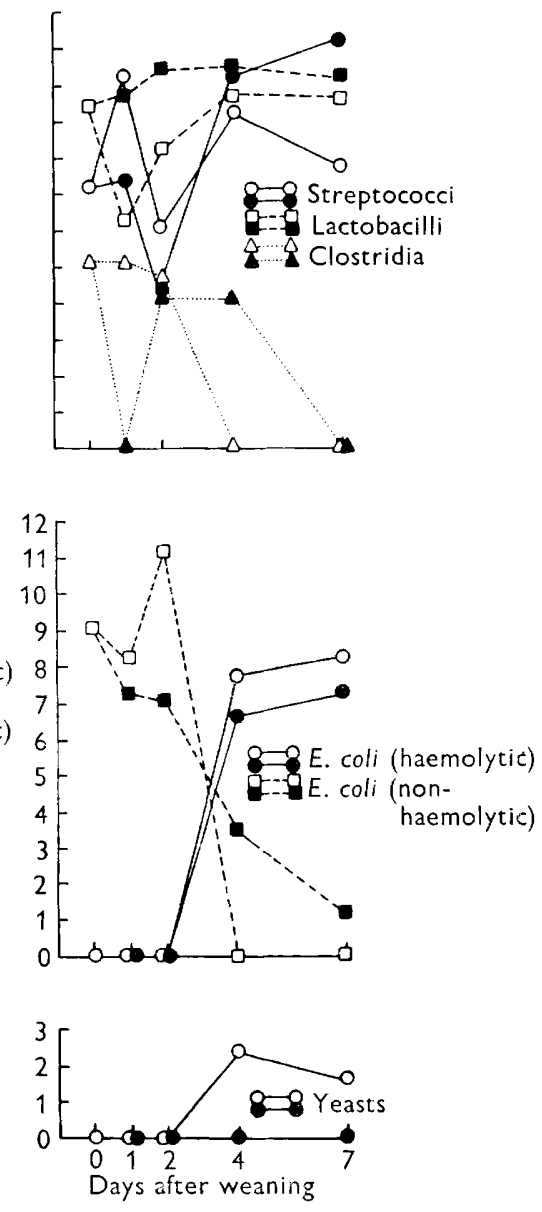

ons Pigs fed on diet 1 (milk)

Pigs fed on diet 2 (milk +- lactobacilli)

FIG. 1.-Numbers of micro-organisms in small-intestinal digesta from pigs fed on milk or on milk incubated with Lactobacillus acidophilus. Samples of digesta were taken at necropsy. 
There were few consistent differences between the components of the intestinal microflora of pigs on the two diets. Streptococci and lactobacilli mostly fluctuated between $10^{6}$ and $10^{11}$ cells, and clostridia between 0 and $10^{6}$ cells per $\mathrm{g}$ dry weight of digesta. Lactobacilli were generally present in slightly greater numbers in animals fed on diet 2.

$E$. coli showed the quantitative and qualitative pattern characteristically following dietary change (Buxton and Thomlinson, 1961; Kenworthy and Crabb, 1963); only non-haemolytic serotypes were present $\left(10^{7}-10^{10}\right.$ cells per $g$ dry weight) in the pre- and immediate post-weaning period, but between the 2 nd and 7 th day after weaning a reduction in the non-haemolytic population was apparent, concomitant with the appearance of haemolytic serotypes.

Bacteroides, present only in trial 1, were not isolated before weaning, but appeared within 2 days of weaning, and were maintained at $10^{5}-10^{9}$ cells per $\mathrm{g}$ dry weight of digesta in pigs fed on diet 1 , and $0-10^{6}$ cells per $\mathrm{g}$ dry weight in pigs fed on diet 2. Proteus was recovered at $0-10^{2}$ cells per g dry weight of digesta in both dietary groups in trial 1 . Yeasts were never isolated from animals before weaning, or from pigs fed on diet 2 in trial 2; they never exceeded $10^{2}$ cells per $g$ dry weight of digesta in the remaining animals.

Analyses of Warburg flask contents at the termination of the experimental period showed all the microbial types isolated from the initial digesta samples to be present in a viable state, although relative numbers had altered.

\section{Decarboxylative activity of intestinal digesta}

The decarboxylative activity of the small-intestinal flora is shown in fig. 2.

Endogenous decarboxylation (due to amino acids present in the digesta) followed a similar pattern in both trials. Before weaning the decarboxylative capacity of the flora was very low; there was an immediate increase post-weaning, however, more apparent in animals fed on diet 1. A subsequent decrease in the rate of decarboxylation was followed by a second increase between the 7 th and 11 th day after weaning in trial 1 , and between the 2 nd and 7 th day after weaning in trial 2. This increase was again more evident in animals fed on diet 1.

The pattern of decarboxylative activity, after addition of the amino acids $l$-arginine, $l$-histidine, $l$-lysine and $l$-ornithine to the digesta, was very similar to that for endogenous decarboxylation; again most activity was shown by the flora of animals fed on diet 1 . Of the added exogenous amino acids, $l$-histidine often stimulated the least increase in decarboxylation, whereas addition of the remainder led to levels of increase very similar to one another.

Amino acid analyses (table I) demonstrated the presence of considerable quantities of free amino acids in the small-intestinal digesta. Of the amino acids regularly catabolised by micro-organisms only arginine was present in small amounts. Thus it would appear that substrate availability is unlikely to be a limiting factor in determinations of total decarboxylative activity of the intestinal flora. 


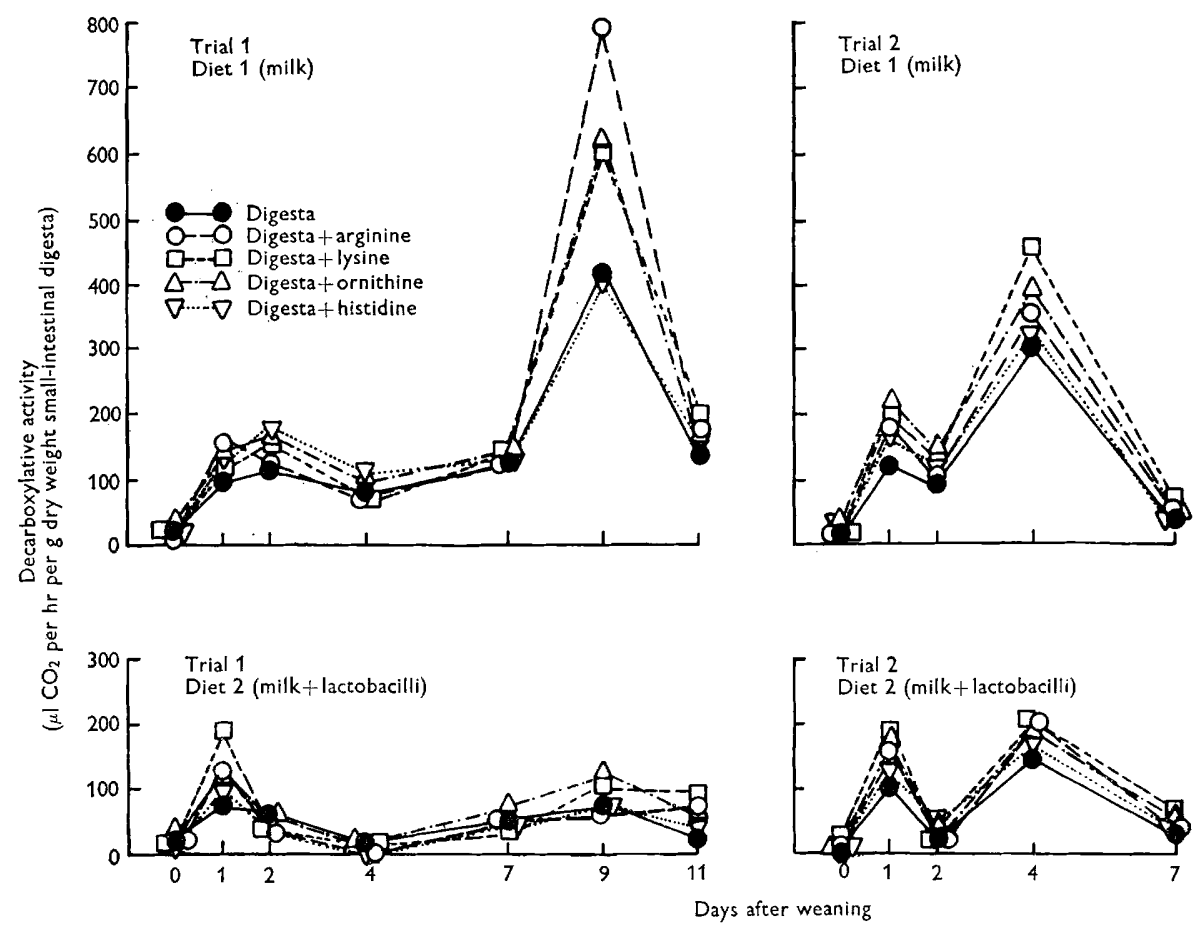

FIG. 2.-In-vitro decarboxylative activity of the small-intestinal microflora in digesta incubated without supplementation, and after the addition of $l$-arginine, $l$-lysine, $l$-ornithine and $l$-histidine.

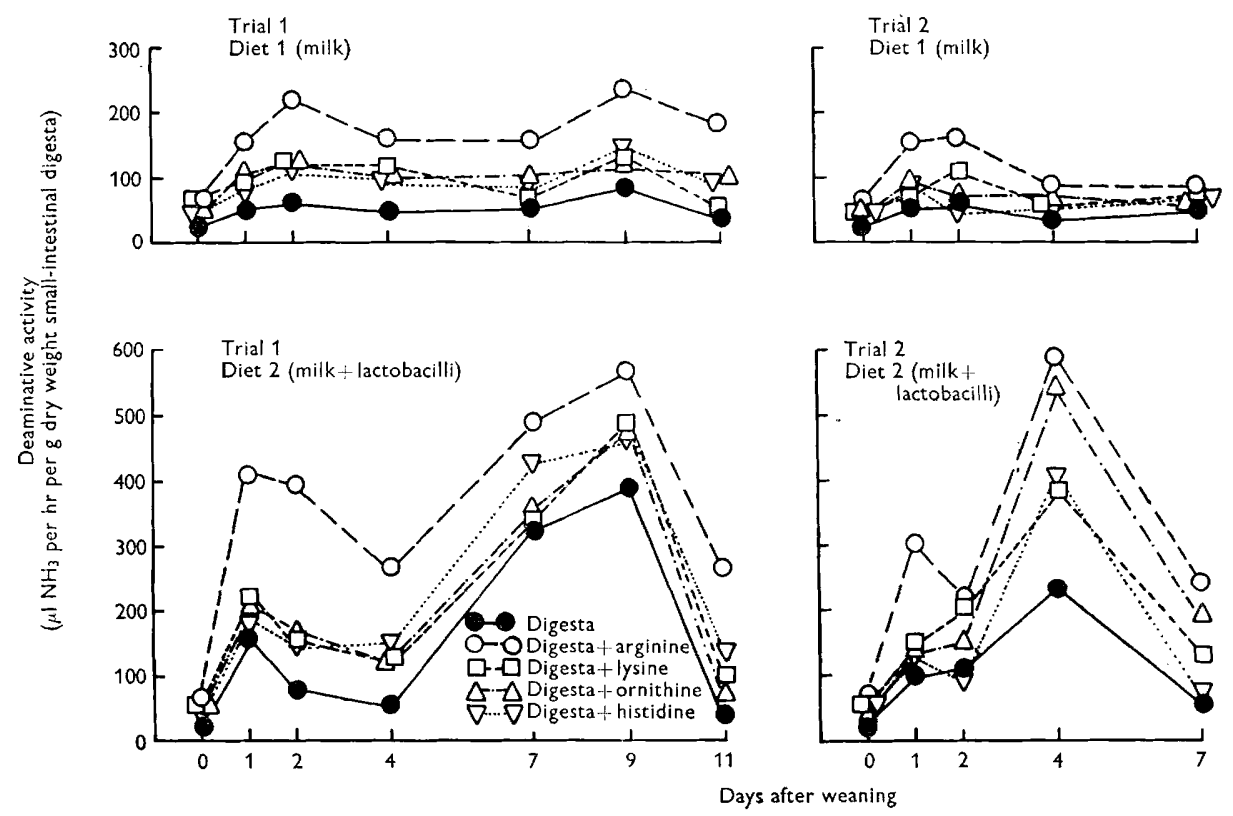

FIG. 3.-In-vitro deaminative activity of the small-intestinal microflora in digesta incubated without supplementation, and after the addition of $l$-arginine, $l$-lysine, $l$-ornithine and $l$-histidine. 


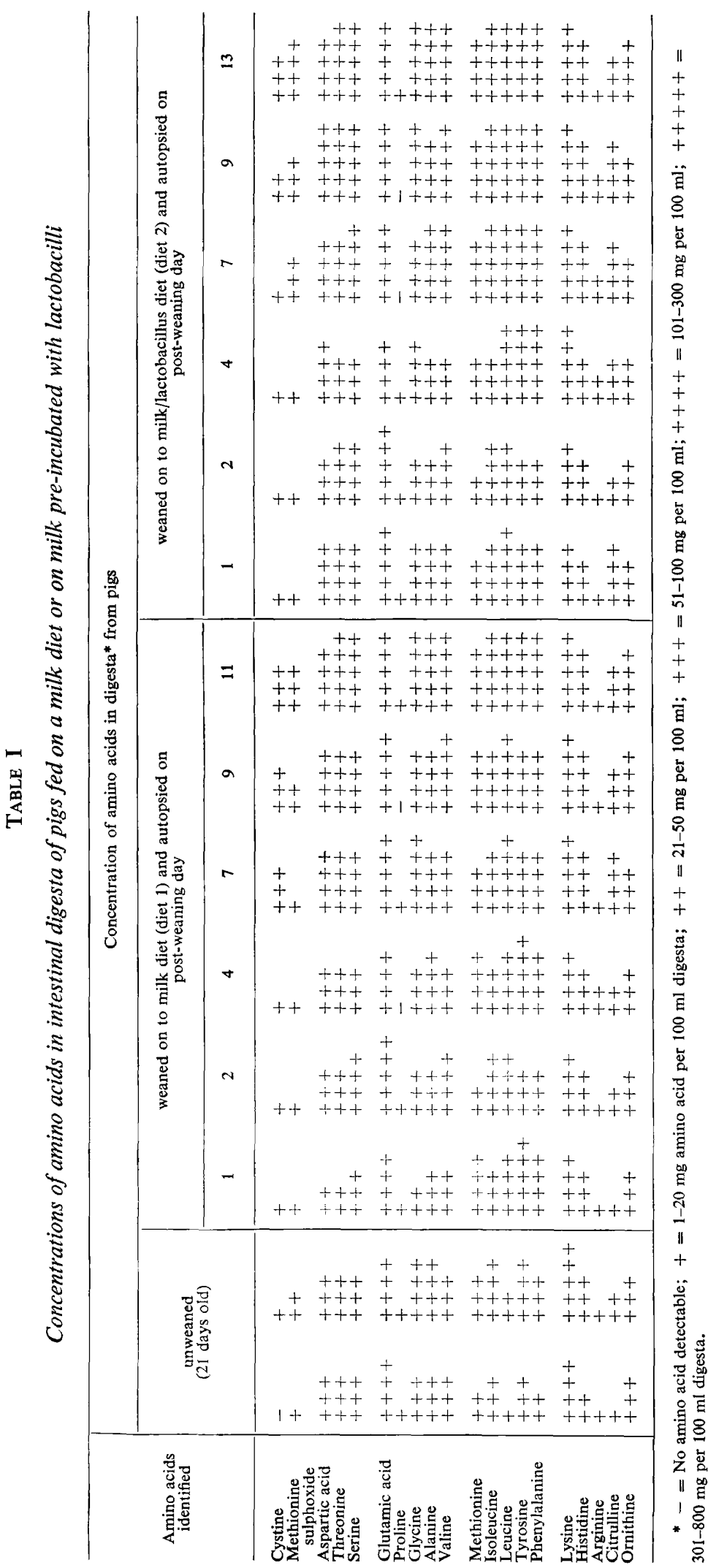




\section{Deaminative activity of intestinal digesta}

The deaminative activity in the unsupplemented digesta was very different for the two dietary treatments (fig. 3). In both trials there was an immediate increase in endogenous deamination after weaning, greater in pigs fed on diet 2. In pigs fed on diet 1 the post-weaning deamination rate remained relatively constant after the initial increase. In animals on diet 2 a second and more dramatic increase in the deamination rate occurred between days 7 and 11 in trial 1 and days 2 and 7 in trial 2, coincident with the second post-weaning increase in decarboxylation.

Addition of exogenous amino acids led to an increase in deamination with a pattern similar to that due to endogenous substrates. Of the added amino acids, $l$-arginine consistently stimulated the greatest increase in deamination, with the remaining amino acids producing results similar to one another.
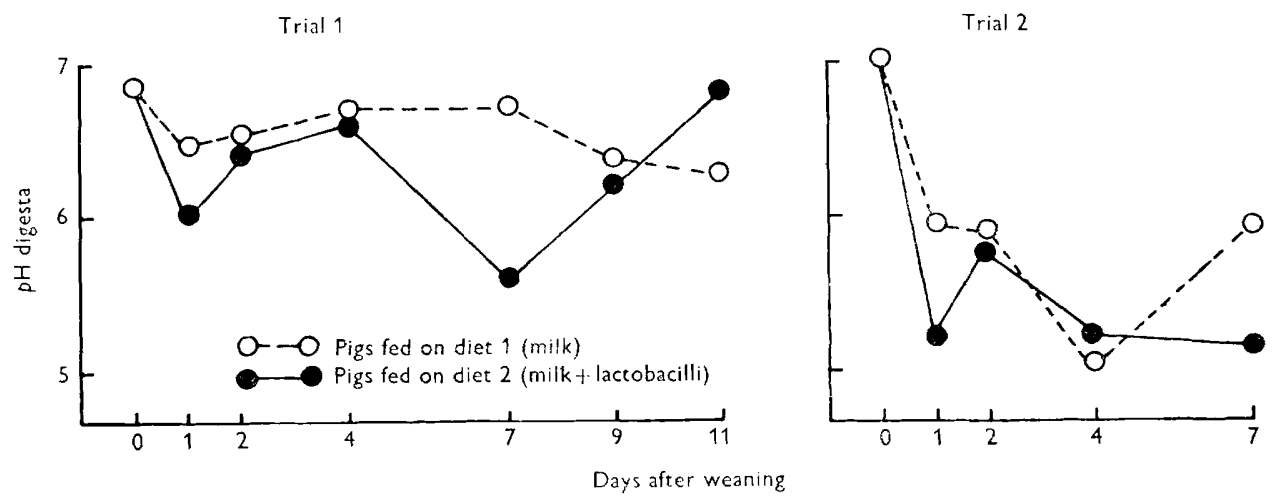

FIG. 4. $-p \mathrm{H}$ of small-intestinal digesta from pigs fed on milk or on milk incubated with lactobacilli. Samples of digesta were taken at necropsy.

\section{pH of intestinal digesta}

The $p \mathrm{H}$ of the small-intestinal digesta, in both trials, remained within the limits $p \mathrm{H} 5 \cdot 0-p \mathrm{H} 7 \cdot 0$ (fig. 4).

The $p \mathrm{H}$ of digesta before weaning was $6 \cdot 7-7 \cdot 0$ whereas values after weaning varied between $5 \cdot 0$ and $6 \cdot 8$. The intestinal $p H$ of animals fed on diet 2 was $0 \cdot 1$ to $1 \cdot 1$ units lower than that of their littermates fed on diet 1 and examined at necropsy on the same day (in only one case was the reverse apparent). The $p \mathrm{H}$ of diet 1 prior to feeding was $6 \cdot 1-6 \cdot 3$ and that of diet $2,5 \cdot 1-5 \cdot 4$.

The $p \mathrm{H}$ of unsupplemented digesta was also recorded at the beginning and end of the 8-hr incubation period in Warburg flasks (fig. 5). Digesta from one group of pigs (diet 1, trial 1), without exogenous amino acids showed an increase in acidity, whilst from all other pigs (trials 1 and 2) it showed a varied response, but rarely with changes greater than $0.5 \mathrm{pH}$ units.

Addition of the amino acids $l$-arginine and $l$-ornithine to digesta in flasks led to an increase in $p \mathrm{H} ; l$-lysine and $l$-histidine had variable effects. Pigs fed on $l$-arginine added to the digesta gave the greatest increase in $p \mathrm{H}(0 \cdot 5-1 \cdot 0 p \mathrm{H}$ 
units on most occasions), followed by $l$-ornithine; addition of $l$-lysine and $l$ histidine on the other hand frequently led to reductions in $p \mathrm{H}$. In pigs on diet 2, $l$-arginine again caused the greatest increase in $p \mathrm{H}$, followed by $l$-lysine; the results with $l$-histidine and $l$-ornithine were variable.

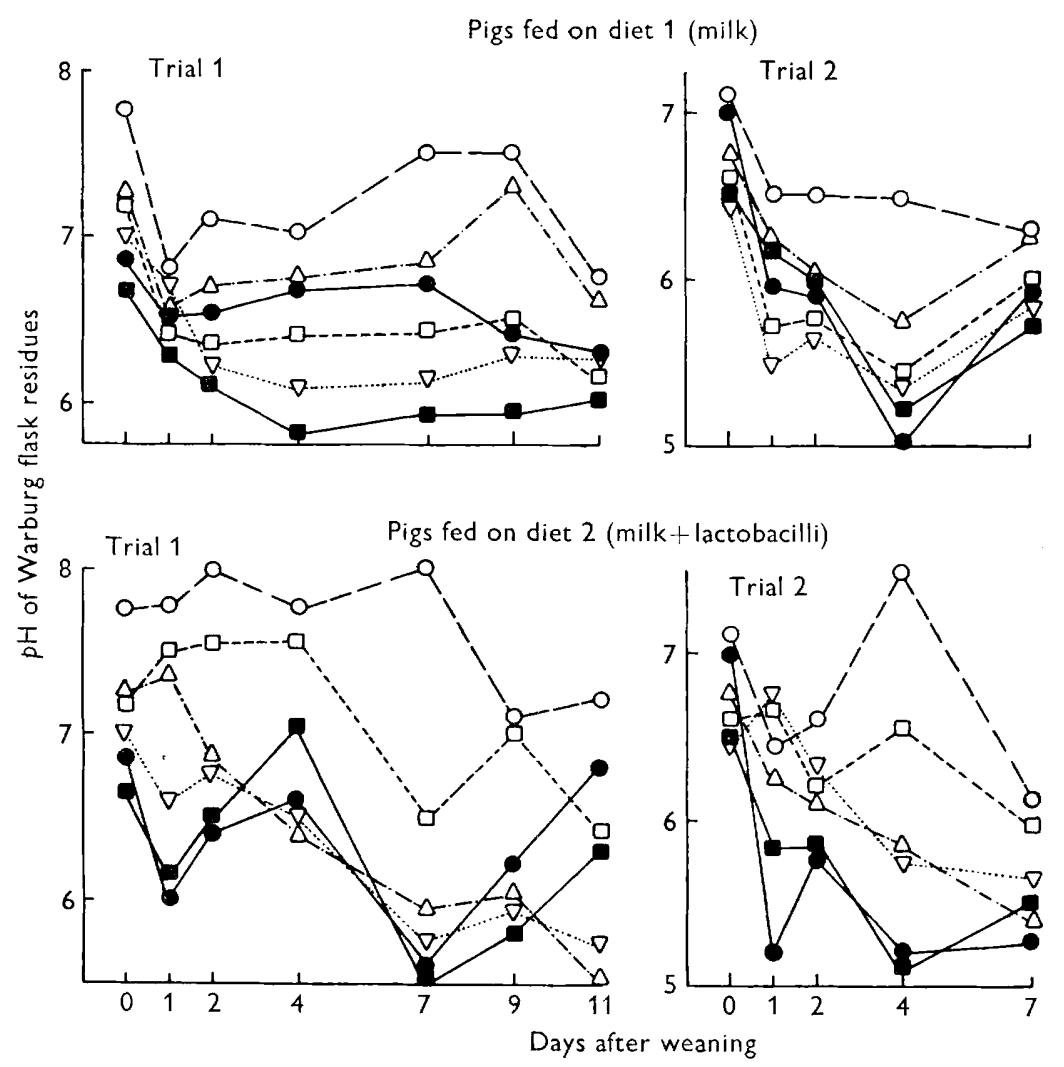

FIG. 5. $-p \mathrm{H}$ of small-intestinal digesta before and after incubation in Warburg flasks. Digesta samples taken at necropsy from pigs fed on milk or on milk incubated with lactobacilli were incubated without supplementation and after the addition of $l$-arginine, $l$-lysine, $l$-ornithine and l-histidine.

$\bullet-\bullet \mathrm{H}$ of digesta at necropsy.

Warburg residue: $p \mathrm{H}$ of digesta after incubation in Warburg flasks.

$\square$ Digesta; $\bigcirc--\bigcirc$ digesta + arginine; $\square---\square$ digesta + lysine; $\triangle-.-.-\Delta$ digesta + ornithine; $\nabla \cdots \cdots \nabla$ digesta + histidine.

Thus the $p \mathrm{H}$ of incubated digesta on several occasions was as high as $p \mathrm{H} 7.5$ and mostly above $p \mathrm{H} 5.7$ in trial 1 , and in trial 2 varied between $p \mathrm{H} 5.0$ and 7.2.

\section{Dry weight of digesta}

The dry weight of the small-intestinal digesta was approximately 11-14 per cent. on the day of weaning (i.e., pre-weaning values), whilst after weaning the values fell, to as low as 4 per cent. in scouring animals (fig. 6). 

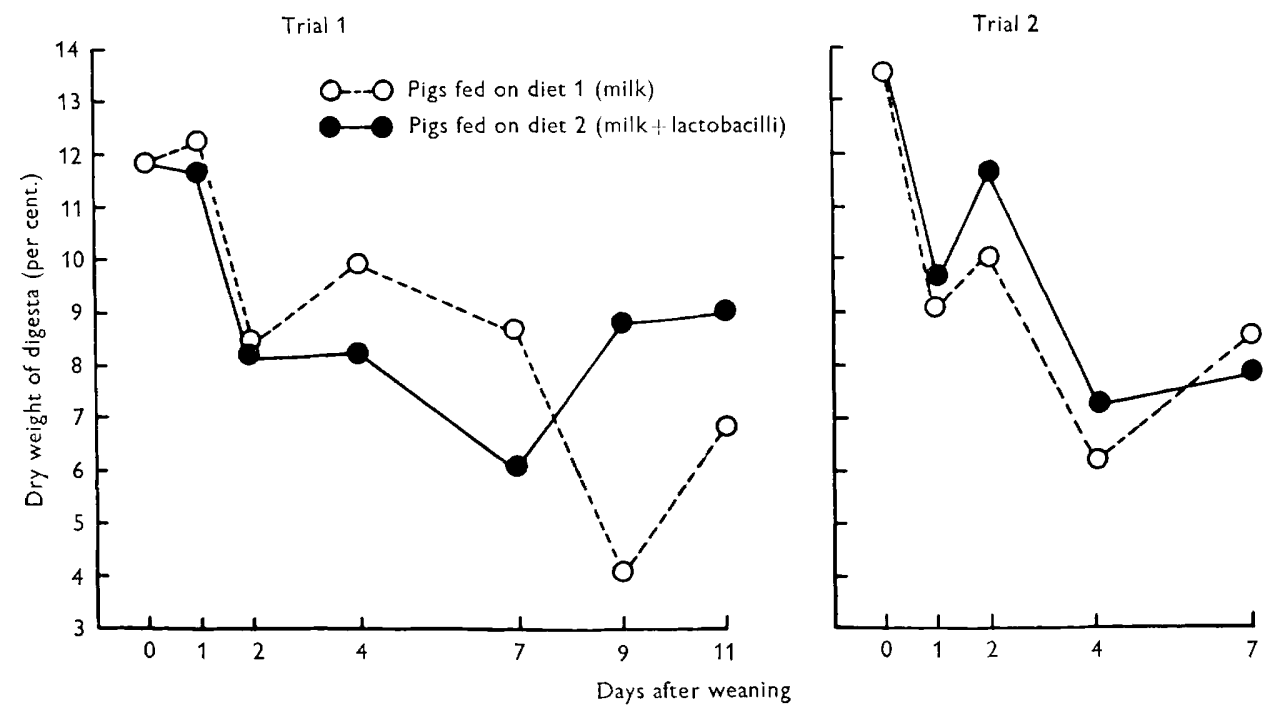

FIG. 6.-Dry weight of small-intestinal digesta from pigs fed on milk or on milk incubated with lactobacilli. Samples of digesta were taken at necropsy.

TABLE II

Liveweights of pigs weaned on to milk or milk incubated with lactobacilli

\begin{tabular}{|c|c|c|c|c|c|c|c|c|c|c|}
\hline \multirow{2}{*}{ Trial } & \multirow{2}{*}{ Diet* } & \multirow{2}{*}{$\begin{array}{l}\text { Pig } \\
\text { no. }\end{array}$} & \multicolumn{7}{|c|}{ Liveweight $(\mathrm{kg})$ on post-weaning day } & \multirow{2}{*}{$\begin{array}{l}\text { Wt gain } \\
\text { (g per day) }\end{array}$} \\
\hline & & & 0 & 1 & 2 & 4 & 7 & 9 & 11 & \\
\hline \multirow[t]{2}{*}{1} & 1 & $\begin{array}{r}3 \\
5 \\
7 \\
9 \\
11 \\
13\end{array}$ & $\begin{array}{l}4 \cdot 8 \\
8 \cdot 3 \\
5 \cdot 9 \\
7 \cdot 0 \\
6 \cdot 0 \\
7 \cdot 5\end{array}$ & $\begin{array}{l}4.5 \dagger \\
8.0 \\
5.8 \\
6.9 \\
5.9 \\
7.7\end{array}$ & $\begin{array}{l}8 \cdot 5 \dagger \\
6 \cdot 1 \\
7 \cdot 3 \\
6 \cdot 2 \\
8 \cdot 3\end{array}$ & $\begin{array}{l}6.6 \dagger \\
7 \cdot 7 \\
6 \cdot 6 \\
8.5\end{array}$ & $\begin{array}{l}7.8 \dagger \\
6.7 \\
8.5\end{array}$ & $\begin{array}{l}6.6 \dagger \\
8.8\end{array}$ & $9.5 \dagger$ & $\begin{array}{r}-300 \\
100 \\
175 \\
114 \\
67 \\
182\end{array}$ \\
\hline & 2 & $\begin{array}{r}4 \\
6 \\
8 \\
10 \\
12 \\
14\end{array}$ & $\begin{array}{l}5.6 \\
6.7 \\
5.9 \\
5.9 \\
7.1 \\
4.2\end{array}$ & $\begin{array}{l}5 \cdot 2 \dagger \\
6 \cdot 2 \\
6 \cdot 5 \\
5 \cdot 8 \\
7 \cdot 0 \\
4 \cdot 3\end{array}$ & $\begin{array}{l}6 \cdot 7 \dagger \\
7 \cdot 0 \\
6 \cdot 4 \\
7 \cdot 9 \\
4 \cdot 8\end{array}$ & $\begin{array}{l}7 \cdot 4 \dagger \\
6 \cdot 7 \\
8 \cdot 4 \\
5 \cdot 4\end{array}$ & $\begin{array}{l}7.5 \dagger \\
8.9 \\
6.2\end{array}$ & $\begin{array}{l}9.7 \dagger \\
6.8\end{array}$ & $7 \cdot 5 \dagger$ & $\begin{array}{r}-400 \\
0 \\
375 \\
228 \\
289 \\
300\end{array}$ \\
\hline \multirow[t]{2}{*}{2} & 1 & $\begin{array}{l}17 \\
19 \\
21 \\
23\end{array}$ & $\begin{array}{l}6 \cdot 2 \\
6 \cdot 6 \\
7 \cdot 1 \\
5 \cdot 5\end{array}$ & $\begin{array}{l}6 \cdot 3 \dagger \\
6 \cdot 5 \\
7 \cdot 1 \\
5 \cdot 3\end{array}$ & $\begin{array}{l}7.0 \dagger \\
7.8 \\
5.6\end{array}$ & $\begin{array}{l}8.0 \dagger \\
5.7\end{array}$ & $6.0 \dagger$ & & & $\begin{array}{r}100 \\
200 \\
225 \\
71\end{array}$ \\
\hline & 2 & $\begin{array}{l}18 \\
20 \\
22 \\
24\end{array}$ & $\begin{array}{l}7.1 \\
5.8 \\
7.5 \\
5.3\end{array}$ & $\begin{array}{l}6 \cdot 8 \dagger \\
5.7 \\
7 \cdot 3 \\
5 \cdot 3\end{array}$ & $\begin{array}{l}6 \cdot 4 \dagger \\
7 \cdot 8 \\
6 \cdot 1\end{array}$ & $\begin{array}{l}8.5 \dagger \\
6.8\end{array}$ & $8.0 \dagger$ & & & $\begin{array}{r}-300 \\
300 \\
250 \\
386\end{array}$ \\
\hline
\end{tabular}

* Diet 1: reconstituted, sterilised spray-dried milk.

Diet 2: diet 1 pre-incubated with Lactobacillus acidophilus.

$\uparrow$ Pig examined at necropsy. 


\section{Liveweights of pigs}

Pigs weaned on to either diet generally lost weight in the $24 \mathrm{hr}$ following weaning (table II). Subsequently, the animals increased in weight, with those fed on diet 2 showing the greater increase.

\section{Discussion}

The current study involved the use of whole digesta, thus introducing into studies on exogenous substrates the complicating presence of endogenous catabolism. However, methods of removing endogenous substrates (Michel, $1961,1966,1968)$ reduce the total microbial population relative to that in whole digesta by up to 60 per cent., the principal loss being by adsorption on to the surface of food particles.

Digesta samples in the present study were incubated immediately after removal from the intestine, to prevent death of anaerobes. We isolated anaerobes from Warburg flasks at the termination of the experiments, but we were unable to do so by Michel's techniques. Furthermore, storage of digesta suspensions as described by Michel $(1961,1966,1968)$ led to large fluctuations in populations, and some genera were completely lost. Michel $(1961,1966,1968)$ has incubated digesta suspensions in Warburg flasks for periods up to $42 \mathrm{hr}$. We were frequently unable to obtain consistent results when incubation periods were extended beyond $10 \mathrm{hr}$. Thus, although our method has disadvantages for catabolic studies of exogenous substrates, it does apparently retain more of the total viable population.

The bacterial amino acid decarboxylases generally appear to react to optimum $p \mathrm{H}$ values lying between 2.5 and 6.0 (Gale, 1946). However, we have found in small-intestinal digesta active decarboxylation at $p \mathrm{H}$ values of up to 7.5. It seems likely that in digesta gross $p \mathrm{H}$ values are misleading and that microhabitat $p \mathrm{H}$ values may be more relevant.

We have demonstrated in-vitro increases in the rates of decarboxylation and deamination of endogenous substrates in the small-intestinal digesta of pigs fed on diets 1 and 2, in the 24- to 48-hr period after weaning. A second increase in decarboxylation occurred between the 7th and 11th day after weaning in trial 1, and between the 2nd and 7th day after weaning in trial 2; the second increase coincided with the occurrence of post-weaning diarrhoea (Hill et al., 1970). The rates of decarboxylation followed trends of change similar to the levels of total small-intestinal, and urinary heterocyclic, amines (Hill et al.). During the diarrhoeic phase deamination increased, but only in pigs fed on diet 2. During both periods of elevated catabolic activity, decarboxylative activity was highest, and deaminative activity lowest, in the digesta of pigs fed on diet 1 . None of the remaining factors quantitated $(p \mathrm{H}$, dry weight and microbial populations of the digesta, and liveweight of the pigs) showed any trends that could be associated with catabolic activities. It has been shown (Nasset, Schwartz and Weiss, 1955; Olmsted, Nasset and Kelley, 1966) that intestinal digesta are rarely deficient in amino acid substrates. We have similarly found considerable amounts of free amino acids to be present in digesta throughout 
the experimental period; suggesting that the levels of catabolic activity were unlikely to be reflections of substrate availability. On most occasions the concentrations of the amino acids (except for arginine) in the unsupplemented digesta were in excess of the amount likely to be catabolised as estimated by Michel (1968), in in-vitro conditions. Furthermore, increases in catabolic activity on addition of exogenous amino acid substrates demonstrated that enzyme availability was not a limiting factor.

Although addition of exogenous amino acids to the digesta does not necessarily give a true reflection of their catabolism by the intestinal microflora, due to the presence of endogenous amino acids, it was apparent that no one amino acid consistently stimulated the greatest increase in decarboxylative activity. Michel (1966) found $l$-histidine to be amongst the most actively catabolised amino acids, but in the present study $l$-histidine on many occasions caused the least increase in decarboxylation. l-Arginine, given orally, has been used to reduce ammonia toxicity (Najarian and Harper, 1958) by a detoxication within the tissues, and in the intestinal lumen Michel (1961) found $l$-arginine to stimulate a relatively poor deaminative activity. In the present study, however, it produced increases consistently greater than the other exogenous amino acids; this was possibly due to the low level of endogenous arginine in the digesta.

The present in-vitro studies of small-intestinal digesta show that during the post-weaning diarrhoeic phase the presence of lactic acid bacteria in the diet coincided with a reduction in the microbial decarboxylative activity and an increase in deaminative activity. The value of the increase in deamination may be to make digesta more alkaline and thus help reduce decarboxylation. The bacterium used in the present study, Lactobacillus acidophilus, was homofermentative, and did not itself deaminate arginine; it therefore cannot itself be responsible for the increases in deamination.

Burnett and Hanna (1963), Kershaw et al. (1966) and Cole et al. (1968) have suggested that the beneficial effects of feeding animals on lactic acid-supplemented diets are largely due to reductions in the numbers of coliforms. In our experiments, however, no consistent differences between the small-intestinal microflora of the two dietary groups were observed, other than slightly increased numbers of lactobacilli in digesta from animals fed on diet 2 , thus negating the common supposition that enteric diseases occur because of changes in the flora at the expense of the lactobacillary component.

The in-vitro observations of small-intestinal and urinary amine concentrations in the weaned pig (Hill et al.) correlate closely with the present in-vitro studies of catabolic activity. It thus seems possible that any prophylactic, therapeutic or combined effects that might accrue from the use of lactic acid bacteria in enteric disorders might involve a reduction in small-intestinal decarboxylative activity, and hence in amine concentration.

\section{SUMMARY}

The effect of dietary lactobacilli on in-vitro deaminative and decarboxylative activities of the small-intestinal microflora has been studied in pigs in relation 
to weaning. Pigs were weaned abruptly at 21 days of age on to a diet of sterile milk or milk incubated with lactobacilli, and measurements of catabolic activity were made on small-intestinal digesta with and without supplementation with $l$-arginine, $l$-histidine, $l$-lysine and $l$-ornithine.

An increase in decarboxylative and deaminative activities was observed within $48 \mathrm{hr}$ after weaning in animals fed on both diets. Decarboxylative activity was highest, and deaminative activity lowest, in digesta from pigs fed on milk without lactobacilli. During a later period, when diarrhoea was observed, there was a second peak of decarboxylative activity in the digesta of animals fed on both diets; but deaminative activity increased only in animals receiving dietary lactobacilli.

Continuous administration of dietary lactobacilli failed to induce any consistent changes in the small-intestinal microflora.

This work was carried out with the technical assistance of Mr E. Prior, Mr J. R. Walker, Miss Jane Workman and the Analytical Section at Colworth House.

\section{REFERENCES}

Anderson, G. W., Hauser, M. M., 1956. Canad.J. Microbiol., 2, 733.

WRIGHT, M. L., AND COUCH, J. R.

Berthelot, A., and Bertrand, D. M. - 1912. C.r. hebd. Séanc. Acad. Sci., Paris, 154, 1643.

Burnett, G. S., AND Hanna, J. . - · 1963. Nature, Lond., 197, 815.

Buxton, A., AND Thomlinson, J. R. . 1961. Res. Vet. Sci., 2, 73.

Cole, D. J. A., Beal, R. M., AND Lus- 1968. Vet. Rec., 83, 459. COMBE, N. D. A.

CowAN, S. T., AND SteEl, K. J. . . . 1965. Manual for the identification of medical bacteria, Cambridge.

Eggerth, A. H., LitTwin, R. J., AND 1939. J. Bact., 37, 187.

DEUTSCH, JOYCE V.

Eyssen, H., AND DE Somer, P. - - . 1965. Ernährungsforschung, 10, 264.

FrançoIs, A. C. . . . . . . . . . 1961. VIII Int. Tierzuchtkongress, Hamburg,

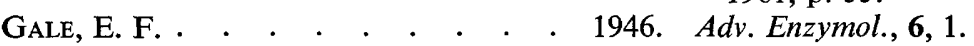

GYÖRGY, P. . . . . . . . . . . 1957. IV Int. Congr. Nutr., Paris, A189.

Hanke, M. T., AND Koessler, K. K. 1924. J. Biol. Chem., 59, 867.

Hill, I. R., Kenworthy, R., AND Porter, 1970. Res. Vet. Sci., 11, 320. P.

Huhtanen, C. N., and Pensack, S. M.

Kenworthy, R., AND Crabb, W. E.

Kershaw, G. F., Luscombe, J. R., AND COLE, D. J. A.

Koch, F. C., AND HaNke, M. E. .

Larson, Nora L., aND HiLl, E. G. . . MELNYKOWYCZ, J., AND JohanNSON, K. R. Michel, M. C. .

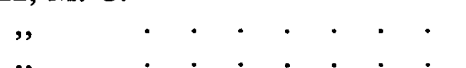

Najarian, J. S., AND HARPer, M. A.

Nasset, E. S., Schwartz, P., AND Weiss, H. V.
1965. Poultry Sci., 44, 830.

1963. J. Comp. Path. Ther., 73, 215.

1966. Vet. Rec., 79, 296.

1953. Practical methods in biochemistry, 6th ed., Baltimore, p. 253.

1960. J. Bact., 80, 188.

1955. J. Exp. Med., 101, 507.

1961. Annls Biol. anim. Biochim. Biophys., 1, 16.

1966. Ibid., 6, 33.

1968. Ibid., 8, 385.

1958. Surg. Gynec. Obstet., 106, 577.

1955. J. Nutr., 56, 83. 
Olmsted, W. W., Nasset, E. S., AND 1966. J. Nutr., 90, 291.

KELLEY, M. L., JR

Perry, T. L., Hestrin, M., Macdougall, 1966. Clin. chim. Acta, 14, 116.

LyNNE, AND HANSEN, SHIRLEY

Porter, P., ANd Kenworthy, R. . . . 1969. Res. Vet. Sci., 10, 440.

Rogosa, M., Mitchell, JoyCe A., AND 1951. J. Bact., 62, 132. WiSEMAN, R. F.

Ross, R. F., ANd Switzer, W. P. 1963. Amer. J. Vet. Res., 24, 622.

Thомаs, C. . . . . . . . . . 1966. In Techniques in amino acid analysis, Chertsey, p. 116.

Umbreit, W. W., Burris, R. H., ANd 1957. Manometric techniques, 3rd ed., MinSTAUFFER, J. F. neapolis, p. 28. 